\title{
O BELO EXPRESSIVO: A COMUNICABILIDADE DOS PADRÕES GRÁFICOS AMERÍNDIOS
}

\author{
SILVIA LOPES DA SILVA MACEDO ${ }^{1}$ \\ MUSEU NACIONAL/UFRJ
}

\begin{abstract}
RESUMO: Neste artigo analiso a prática de grafismos e de desenhos realisada pelos amerínidios Wayãpi da Guiana francesa. Viso com isso evidenciar o caráter comunicativo próprio que define esta prática estética. Para tanto são analisados exemplos etnográficos de práticas e de usos autais de pinturas corporais e de desenhos produzidos por membros desta população ameríndia da aldeia de Trois Sauts (Guiana Francesa).
\end{abstract}

PALAVRAS-CHAVE: grafismo; desenhos; amerínidios Wayãpi; comunicação estética.

ABSTRACT: In this paper I analyse some drawings and graphic practices realized by the South American Indians Wayãpi of French Guyana. The purpose here is to explore the communicative patterns that define this esthetical practice. To do so ethnographic examples of practices and uses of these body paintings and drawings made by members of the wayapi population are analysed.

KEYWORDS: graphic patterns; drawings; Wayãpi Indians; aesthetical communication.

Ao procurar entre os índios Wayãpi da aldeia de Trois Sauts, Guiana francesa, 'informantes' dispostos a trabalhar sobre o tema desenhos e grafismos, recebi vários "não" como resposta. Isso até o dia em que um homem mais velho se dispôs a trabalhar comigo algumas horas por dia.

Após nosso primeiro encontro, quando este senhor esboçou em um papel alguns motivos gráficos que ele conhecia, recebi a visita de um outro homem, mais velho, proveniente de uma família e grupo local diferentes do primeiro. Este homem, um dos grandes cantores da aldeia de Trois Sauts, nunca tinha ido à escola. Ele veio à minha casa quando eu escrevia notas em meu caderno de campo. Esse senhor conhecia meus interesses etnológicos e inicialmente havia se recusado a trabalhar comigo. Ele entrou na casa e me pediu uma folha de papel. Começou a

\footnotetext{
1 Doutora em Antropologia Social e Etnologia pela EHESS (Paris). Pos-doutoranda pelo Museu Nacional/UFRJ, bolsista CNPQ. E-mail: silvia.lopesmacedo@gmail.com .
}

Espaço Ameríndio, Porto Alegre, v. 1, n. 1, p. 62-72, jul./dez. 2007. 
'escrever' longas linhas curvilíneas no sentido vertical do papel que ultrapassavam os limites da folha. Ele escrevia, assim como eu. Uma vez terminada sua escrita ele me deu o papel e me disse : "é assim.Você queria saber, não é?"

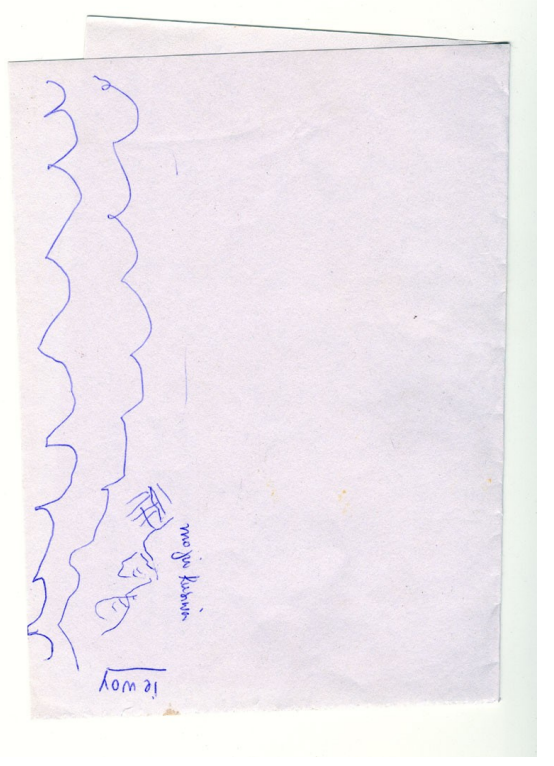

Ao pedir mais informações sobre o desenho ${ }^{2}$ o senhor me explicou que aquele era o rastro da anaconda.

Mas a qual conhecimento aquele desenho esboçado por ele me dava acesso?

Os grafismos da anaconda, os desenhos de sua pele, de seus ossos, são padrões recorrentes dos grafismos ameríndios. E o que vemos nos grafismos wayãpi não é diferente. Entre os grafismos wayãpi chamados kusiwa, a anaconda é um dos padrões bastante desenhado.

Kusiwa e ekosiware são os termos em wayãpi para designar o ato de desenhar, de escrever e de realizar grafismos.

Os Wayãpi são índios de língua da família tupi-guarani que moram em aldeias no Amapá, Brasil, e na Guiana francesa. Os Wayãpi do Amapari tiveram seus grafismos kusiwa declarados Patrimônio Oral e Imaterial da Humanidade pela UNESCO em 2003.

\footnotetext{
${ }^{2}$ Os desenhos aqui reproduzidos são de autoria dos ameríndios Wayãpi da aldeia de Trois Sauts, Guiana Francesa. Os dois primeiros desenhos foram produzidos por homens adultos de maior idade, os dois últimos desenhos são de crianças wayãpi (8 anos) que frequentam a escola da aldeia.
} 
SILVIA LOPES DA SILVA MACEDO - O belo expressivo...

Os grafismos wayãpi são pintados sobre o corpo assim como sobre objetos. Eles são realizados com a tintura do urucum, do genipapo e de resinas. Os motivos kusiwa compreendem motivos aprendidos em tempos imemoriais - contados nos relatos míticos-, e motivos aprendidos em outras situações como na escola, em viagens, em guerras ou em outras situações de contato e de troca.

Na Guiana francesa os Wayãpi são mais econômicos no uso dos padrões kusiwa. Entretanto eles os reconhecem, e sua origem e aprendizagem são contadas em uma série de relatos míticos sobre a origem da diferenciação das espécies que se assemelha àquela dos relatos contados pelos Wayãpi do Brasil.

A antropóloga Françoise Grenand conta (TINOCO, 2006) que quando ela e seu marido encontraram os Wayãpi de Trois Sauts no início dos anos 70, estes não usavam pinturas corporais devido à baixa demográfica provocada pelas epidemias. Segundo a antropóloga, o longo período de epidemia, a quantidade de mortos e os interditos relativos ao uso da pintura em estados liminares - como o de luto-, fizeram com que as pinturas caíssem em desuso.

Porém, em meu último campo (2004), contrariamente à hipótese sobre a perda deste conhecimento que poderíamos supor, tendo em vista esta experiência traumática das epidemias, os Wayãpi da Guiana realizaram vários grafismos sobre seus corpos e sobre folhas de papel. Alguns desenhos foram realizados em mim, como o do jabuti (jawi) e o da pele da anaconda (moju). Servi igualmente de cobaia para outras aplicações, como aquelas de motivos florais e de corações realizadas por meninas pequenas sobre meu rosto, desenhados com batom e lápis de maquiagem.

A competência na realização dos grafismos kusiwa pelos Wayãpi da Guiana é menor do que aquela que vemos entre os Wayãpi do Brasil. Os traços são menos firmes, o repertório menos extenso. No entanto, minha presença e insistência fizeram com que surgisse um debate na aldeia sobre o tema e incentivaram a retomada das pinturas. Vários motivos foram realizados pelos Wayãpi de Trois Sauts, motivos estes que encontramos igualmente do outro lado da fronteira, entre os Wayãpi do Brasil. As pessoas mais velhas desenharam os motivos anaconda (moju), borboleta (panã), ralador de mandioca (rykyry) e jabuti (jawi). Os 
mais jovens (até 20 anos) inovaram desenhando marcas publicitárias, nomes, personagens de desenhos animados, letras e palavras.

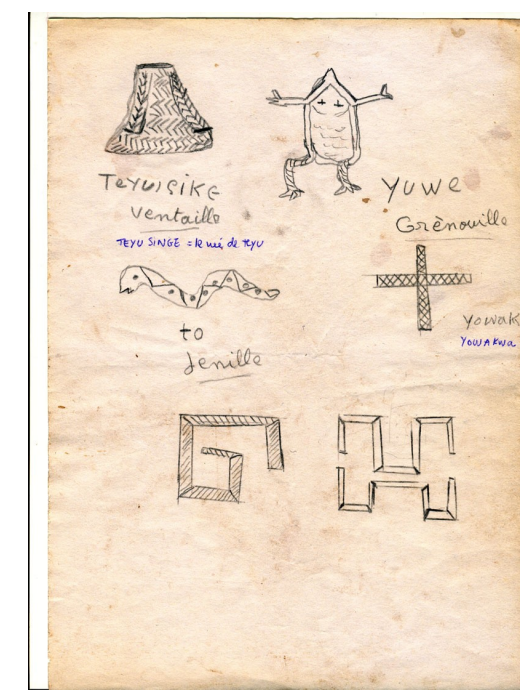

\section{Aprendizagem e comunicação: os padrões gráficos kusiwa}

Os mitos que relatam a aprendizagem dos padrões kusiwa descrevem o tempo primordial como um tempo sem especiação. Neste tempo todos os seres tinham aparência similar. O herói criador da humanidade, Janejar, decide então diferenciar as espécies e organiza uma festa para realizar esta especiação. É a partir deste momento que os seres começaram a morar em espaços determinados e ter formas diversas. Os seres que caem na água durante a festa tornam-se peixes, aqueles cujos corpos foram pintados com os excrementos coloridos da anaconda (moju) e que partiram da festa voando tornam-se pássaros, e assim por diante.

A observação destas espécies, de seus ossos, da pele da anaconda, das espinhas de peixe e da pele de animais selvagens ensinou aos Wayãpi motivos gráficos que eles passaram a reproduzir em suas pinturas. Além destes motivos, aprendidos em tempos míticos a partir da observação das peles e ossos de diferentes espécies, os motivos provenientes de contatos recentes com outros povos também passaram a fazer parte do acervo gráfico wayãpi. 
No mito recolhido entre os Wayãpi do Amapari por Gallois (1988), a autora relata como estes ameríndios aprenderam e se apropriaram dos motivos kusiwa:

Os motivos decorativos foram observados no corpo da Anaconda quando esta, metamorfoseada num atraente rapaz, seduziu uma moça em resguardo. Já mencionei a seqüência do mito dos 'animais sedutores': quando os irmãos da moça matam o intruso, eles podem observar os belos motivos com que o sedutor estava pintado. E útil lembrar, neste ponto, que a maioria dos motivos kusiwa representam animais como peixes, jacarés, sapos e cobras d'água. São as criaturas de moju, que ela trazia pintadas na pele (GALLOIS, 1988, p. 274).

Os motivos kusiwa, nos descreve Gallois (2002) para os Wayãpi do Amapari (Brasil), resultam da combinação de quatro elementos gráficos: o pontilhado (wiriwiri); as linhas paralelas (kã'gwer); as linhas cruzadas (rykyry) e as linhas quebradas (moj). Segundo a autora, eles têm uma 'função' que ultrapassa a 'função estética'. Os motivos têm funções simbólicas e culturais e são uma forma de estabelecer uma comunicação com outros domínios cosmológicos, religiosos e xamânicos, todos estes constitutívos do mundo wayãpi.

No caso da pintura corporal, a pintura negra sobre o corpo humano torna os homens belos, e também visíveis aos mortos, aos seres sobrenaturais. Esta pintura facilita o contato e a interação entre esses seres. O vermelho, ao contrário, protege os homens dos ataques de certos seres, porque o vermelho esconde e protege os homens.

A pintura, os grafismos têm, para além da representatividade, uma agência sobre os homens e sobre os seres. Os grafismos estabelecem uma passarela e tornam visível, em um mesmo suporte, a pluralidade de formas e seres.

Essa comunicação entre domínios cosmológicos não é simples nem imediata, como nos adverte Gallois (2002) e Barcelos Neto (2002). O grafismo não é uma 'legenda' da cosmologia, nem a cosmologia uma simples explicação do grafismo (BARCELOS NETO, 2002, p. 115). O grafismo é uma forma de comunicação com seres de outros domínios cosmológicos que estão em relação com os ameríndios. Esta forma de 
SILVIA LOPES DA SILVA MACEDO - O belo expressivo...

comunicação é constitutiva de um sistema de troca, de guerra e de predação que os amerínidios estabelecem com esses seres.

A relação entre os grafismos, a estética, a organização social e a cosmologia em populações ameríndias vem sendo trabalhada por alguns autores como Guss (1990); Vidal (1992); Gallois (1992; 2002); Lopes da Silva e Farias (1992); Müller (1992; 1993); Gow (1999; 2001); Barcelos Neto (2002); Van Velthem (2003); Lagrou (2007), entre outros.

Vidal e Lopes da Silva (1992) escreveram em artigo sobre a antropologia estética, o papel central da estética e da arte gráfica nas sociedades ameríndias. Segundo as autoras, por meio da arte gráfica e de suas expressões estéticas é possível apreender os significados cognitivos pelos quais as sociedades organizam e exprimem suas percepções de si e do mundo. As manifestações artísticas seriam 'condensados de significantes culturais' (idem ibidem, 288) que conjugam habilidade técnica do artista - enquanto individo e enquanto membro de um grupo social - às qualidades formais do desenho e aos conteúdos simbólicos.

A análise de Van Velhtem (2003) da estética wayana e da produção do belo - segundo o sentido atribuído pelos índios a este conceito -, também contribui neste sentido. É por meio da análise da estética wayana que a autora nos permite ver a complexidade de relações de produção e de predação constitutivas da cosmologia wayana. A produção e a simbólica dos objetos e dos corpos valorizados e estéticos segundo os padrões wayana-, evidenciam esta comunicação e interação entre os seres vivos e o mundo que os circunda - um mundo povoado por animais, inimigos e seres sobrenaturais.

O trabalho de Müller (1993) sobre a forma tayngava nos permite igualmente ver, por meio do exemplo do grafismo asuriní e de suas formas geométricas, esta relação entre seres e domínios cosmológicos que ultrapassa a relação de representação pictórica. Em sua análise, Müller mostra como os desenhos tayngava não são apenas uma representação-imagem e sim a realização de uma existência em si mesma. Os desenhos são constitutivos do ser que 'representam', um ser cuja imagem é parte constitutiva de sua existência. 


\section{Padrões gráficos e desenhos entre os Wayãpi da Guiana francesa}

No caso dos Wayãpi da Guiana, os motivos gráficos também realizam esta comunicação simbólica. Os grafismos, além de expressões do belo, são meios de comunicação, de representação e de agência que ultrapassam a comunicação entre os homens, estendendo-se para todos os seres presentes no cosmos. O grafismo é uma das possíveis formas existentes de comunicação e contribui para o estabelecimento de interações entre os seres.

A análise dos desenhos produzidos pelos Wayãpi da aldeia de Trois Sauts, Guiana francesa, pode ser interpretada neste sentido. Durante minha estada na aldeia de Trois Sauts incentivei o debate sobre o grafismo e vários desenhos foram realizados por estes ameríndios sobre seus corpos e em papel sulfite. Porém, além dos grafismos kusiwa, outros desenhos foram realizados - como as flores em meu rosto e no rosto de outras meninas, ou como as tatuagens com símbolos de publicidade e letras no corpo dos meninos.
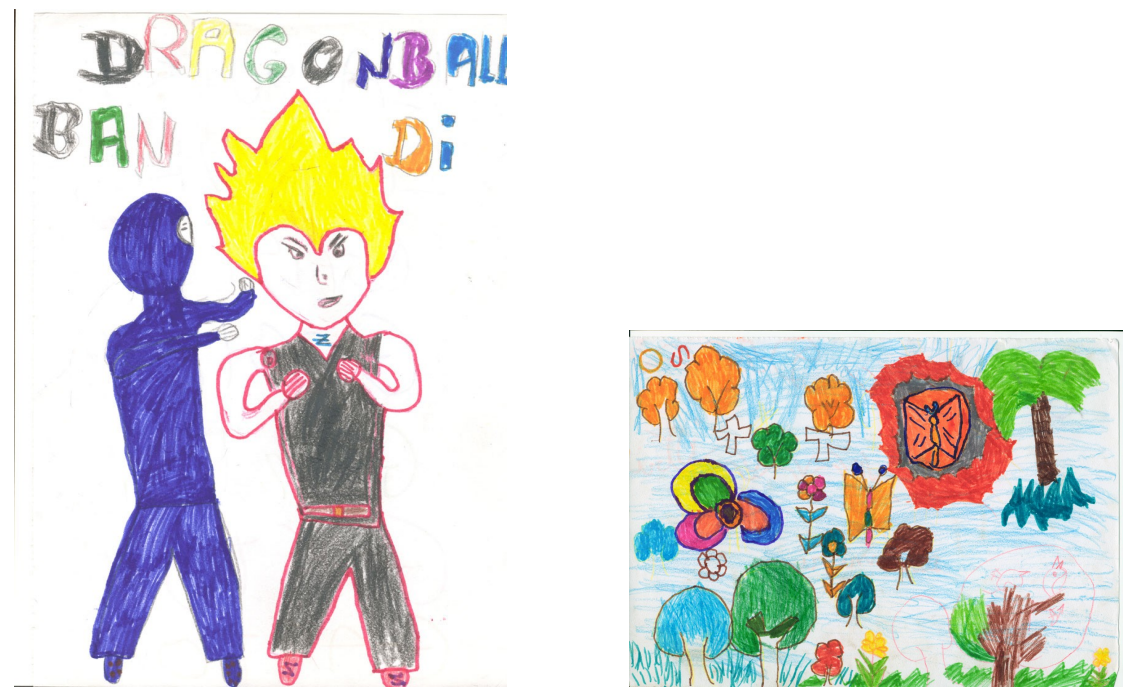

A produção de desenhos, principalmente infantis, em papel sulfite é enorme. Durante minha estada de 2004 recolhi 89 desenhos de crianças que vinham produzi-los em minha casa nas horas extraescolares. A maioria destes desenhos são desenhos figurativos e podem ser divididos em cinco categorias segundo os temas abordados: 1) 
SILVIA LOPES DA SILVA MACEDO - O belo expressivo...

árvores e flores; 2) aldeia e suas casas; 3) o beija-flor; 4) temas cosmológicos (máscaras ou seres sobrenaturais); 5) personagens de desenho animado (homem aranha, entre outros).

A diferença formal entre estes desenhos e os motivos gráficos kusiwa poderia sugerir a hipótese de um desconhecimento dos padrões kusiwa pelos jovens. Se por um lado é fato que os homens mais velhos (mais de 40 anos) tendem a desenhar apenas os padrões kusiwa, por outro lado é verdade que os mais jovens são igualmente capazes de fazê-los. Vejamos um exemplo.

Durante uma atividade em sala de aula na escola de Trois Sauts a professora distribuiu o desenho de um peixe e pediu para os alunos o colorirem. Boa parte dos alunos, em sua maioria de 8 anos de idade, desenharam no corpo do peixe padrões gráficos kusiwa, evidenciando sua competência e conhecimento destes padrões.

Como já avançamos acima, a idéia de representação não é suficiente para compreender os desenhos e grafismos ameríndios. Os grafismos agem para além da representação sobre homens e seres. Eles tornam visíveis e, mais do que isso, fazem existir e se transformar, em um mesmo suporte, a pluralidade de formas e de seres existentes no cosmos.

Para os Wayãpi uma boa interação com o mundo depende da propriedade e da beleza de seus desenhos. O desenho permite aos homens estabelecer relações boas e próprias com o mundo invisível.

Lembremos que beleza e propriedade da relação são qualidades complementares e são condição sine quoi non para se estabelecer uma boa relação com os seres que povoam o mundo wayãpi, seres estes junto aos quais os ameríndios devem negociar sua existência.

Estar belo, estar pintado é tornar-se visível. Os motivos, os desenhos tornam possível e influem sobre o tipo de interação que os humanos estabelecem com outros seres. Uma aplicação errônea pode, por exemplo, possibilitar uma predação.

Mas estar belo quer dizer também ter realizado com propriedade o desenho. Um desenho BELO é igualmente um desenho BOM. A beleza depende da boa realização dos padrões, do bom controle da técnica. 
SILVIA LOPES DA SILVA MACEDO - O belo expressivo...

As crianças de Trois Sauts me perguntavam insistentemente se seus desenhos eram belos e bons. Mas o que diziam quando me perguntavam isso?

Quando o faziam elas estavam procurando se assegurar da propriedade de seus desenhos na constituição de uma boa e apropriada relação com um outro ser, desta vez visível, qual seja, eu. Seus desenhos e sua temática - flores, personagens de histórias, letras do alfabeto e filmes - eram imagens que elas reconheciam e me atribuíam como padrões pertencentes ao 'meu', i.e. dos brancos, padrão gráfico.

Aqui também a produção de belos e bons desenhos era uma forma de constituir com esses outros, os 'brancos' - os paraisiko (franceses) e os karaiko (brasileiros) - uma boa relação. Para atingir este fim as crianças utilizavam da prática cultural do grafismo para estabelecer uma boa relação com estes outros - potencialmente inimigos e perigosos, domesticando-os por meio da pintura e do desenho, e incorporando-os por meio da utilização de seus padrões.

Além disto, no caso dos desenhos, estes não eram realizados sobre o corpo, mas sobre o papel, um suporte onipresente do mundo dos 'brancos' reconhecido pelos ameríndios como meio privilegiado dos 'brancos' de estabelecerem suas relações.

A incorporação e utilização dos padrões gráficos 'karaiko' e 'paraisiki' nos desenhos das crianças e jovens seguiria então esta mesma lógica que define o uso e a simbólica dos grafismos kusiwa wayãpi.

Isto é, como para os padrões kusiwa, os padrões utilizados nos desenhos das crianças vêm de fora, eles são atribuídos a outros seres e têm uma qualidade comunicacional que ultrapassa a representação figurativa. Estes padrões são meios de estabelecer relações de comunicação com outros seres - que aqui são os brancos-, e contribuem à concepção e existência mesma destes outros seres.

Ao se apropriarem de uma técnica e de uma estética gráfica estrangeiras as crianças procuravam estabelecer uma comunicação eficaz com outros seres presentes em seu mundo atual - os 'brancos' a partir da reprodução de seus padrões gráficos. Assim como para o velho senhor que desenhou os rastros da anaconda, meu acesso à uma série de conhecimentos e formas de relação próprias ao mundo wayãpi 
SILVIA LOPES DA SILVA MACEDO - O belo expressivo...

se dava pela realização e leitura de seu desenho, para as crianças o desenho dos padrões que identificavam como sendo dos 'brancos' - i.e. flores, personagens de desenho animado, etc- permitia o estabelecimento de uma boa e apropriada relação com estes outros.

\section{Referências bibliográficas}

BARCELOS NETO, Aristóteles. A arte dos sonhos: uma iconografia ameríndia. Lisboa: Assirio \& Alvim, 2002.

GALLOIS, Dominique. O Movimento na cosmologia Waiãpi: criação, transformação e expansão do universo. Tese de doutorado. São Paulo: FFLCH/USP, 1988.

. Expressão gráfica e oralidade entre os Wajãpi do Amapá-Brasil. Boletim do Museu do Índio, Rio de Janeiro, n. 9, out. 2002.

GOW, Peter. Piro designs: Painting as Meaningful action in an Amazonian Culture. Journal of the Royal Anthropological Institute, Londres, new series 5, 1999.

. An Amazonian Myth and its history. Oxford: Oxford University Press, 2001.

GUSS, David. To Wave and Sing: art, symbol and narrative in the south American Rain Forest. Los Angeles: University of California Press, 1990.

LAGROU, Elsje Maria. A fluidez da Forma: arte, alteridade e agência em uma sociedade amazônica (Kaxinawa, Acre). Rio de Janeiro: Topbooks, 2007.

LOPES DA SILVA, Aracy; FARIAS, Agenor. Pintura corporal e sociedade: os 'partidos' Xerente. In: VIDAL, Lux (Org.). Grafismo Indígena. São Paulo: Nobel/Fapesp/Edusp, 1992.

MÜLLER, Regina Pollo. Tayngava, a noção de representação na arte gráfica. In: VIDAL, Lux (Org.). Grafismo Indígena. São Paulo: Nobel/Fapesp/Edusp, 1992.

Os assuriní do Xingu: História e Arte. Campinas: UNICAMP, 1993.

TINOCO, Silvia Lopes da Silva Macedo. Ekolya et Karetajar: maître de l'école, maître de l'écriture. L'incorporation de l'écriture et de l'école par les amérindiens wayãpi de l'Amapari (Brésil) et de l'Oyapock (Guyane française). Tese de doutorado, Paris: Ecole des Hautes Etudes en Sciences Sociales, 2006.

VAN VELTHEM, Lucia. O belo é a fera: a estética da produção e da predação entre os Wayana. Lisboa: Assírio \& Alvim, 2003. 
SILVIA LOPES DA SILVA MACEDO - O belo expressivo...

VIDAL, Lux (Org.). Grafismo Indígena. São Paulo: Nobel/Fapesp/Edusp, 1992.

VIDAL, Lux e LOPES DA SILVA, Aracy. Antropologia estética: enfoques teóricos e contribuições. In: VIDAL, Lux (Org.). Grafismo Indígena. São Paulo: Nobel/Fapesp/Edusp, 1992. 